\title{
Improvement of SuperDARN velocity measurements by estimating the index of refraction in the scattering region using interferometry
}

\author{
R. G. Gillies, ${ }^{1}$ G. C. Hussey, ${ }^{1}$ G. J. Sofko, ${ }^{1}$ K. A. McWilliams, ${ }^{1}$ R. A. D. Fiori, ${ }^{1,2}$ \\ P. Ponomarenko, ${ }^{3}$ and J.-P. St.-Maurice ${ }^{1}$ \\ Received 5 December 2008; revised 27 April 2009; accepted 5 May 2009; published 10 July 2009.
}

[1] In past calculations of convective velocities from Super Dual Auroral Radar Network (SuperDARN) HF radar observations, the refractive index in the scattering region has not been taken into account, and therefore the inferred ionospheric velocities may be underestimated. In light of the significant contribution by SuperDARN to ionospheric and magnetospheric research, it is important to refine the velocity determination. The refractive index in the ionosphere at SuperDARN observation $F$ region altitudes has typical values between 0.8 and close to unity. In the scattering region, where conditions are more extreme, the index of refraction may be much lower. A simple application of Snell's law in spherical coordinates (Bouguer's law) suggests that a proxy for the index of refraction at the scattering location can be determined by measuring the elevation angle of the returned ionospheric radar signal. Using this approximation for refractive index, the Doppler velocity calculation can be refined for each SuperDARN ionospheric echo, using the elevation angles obtained from the SuperDARN interferometer data. A velocity comparison of DMSP and SuperDARN observations has revealed that the SuperDARN speeds were systematically lower than the DMSP speeds. A linear regression analysis of the velocity comparisons found a best fit slope of 0.74 . When the elevation angle data were used to estimate refractive index, the best fit slope rose $12 \%$ to 0.83 . As most SuperDARN radars employ an interferometer antenna array for elevation angle measurements, the improvement in velocity estimates can be done routinely using the method outlined in this paper.

Citation: Gillies, R. G., G. C. Hussey, G. J. Sofko, K. A. McWilliams, R. A. D. Fiori, P. Ponomarenko, and J.-P. St.-Maurice (2009), Improvement of SuperDARN velocity measurements by estimating the index of refraction in the scattering region using interferometry, J. Geophys. Res., 114, A07305, doi:10.1029/2008JA013967.

\section{Introduction}

[2] The global network of Super Dual Auroral Radar Network (SuperDARN) [Greenwald et al., 1995] radars measure ionospheric convection in the auroral and polar regions. These HF radars rely on ionospheric refraction to bend the transmitted waves until they are perpendicular to the magnetic field lines. When this occurs, field-aligned ionospheric irregularities can coherently scatter the wave back to the radar. The Doppler shift of the returned wave is used to determine the line-of-sight velocity of the plasma in the scattering region. If it is assumed that the scattering

\footnotetext{
${ }^{1}$ Institute of Space and Atmospheric Studies, University of Saskatchewan, Saskatoon, Saskatchewan, Canada.

${ }^{2}$ Natural Resources Canada, Geomagnetic Laboratory, Ottawa, Ontario, Canada.

${ }^{3}$ Space Physics Group, University of Newcastle, Callaghan, New South Wales, Australia.

Copyright 2009 by the American Geophysical Union. 0148-0227/09/2008JA013967\$09.00
}

region has a refractive index of unity, the apparent line-ofsight velocity of the scatterer, $v_{s, a}$ is

$$
v_{s, a}=\frac{\Delta \omega_{D} c}{2 \omega}
$$

where $\Delta \omega_{D}$ is the Doppler shift of the received wave, $\omega$ is the frequency of the radar wave, and $c$ is the speed of light in a vacuum [Baker et al., 1995]. However, the speed of the radar wave in a scattering region of refractive index $n_{s}$ is $c / n_{s}$, so the scatterer velocity $v_{s, c}$ accounting for the refractive index is given as [Ginzburg, 1964]

$$
v_{s, c}=\frac{\Delta \omega_{D} c}{2 \omega} \frac{1}{n_{s}}
$$

The index of refraction in the $F$ region ionosphere, where the HF radar waves are backscattered, is typically less than unity. Because the current SuperDARN Doppler velocity calculation does not account for the index of refraction effect, the ionospheric convection velocity will be underestimated if the index of refraction differs significantly from 
unity. Previous velocity comparisons have revealed that SuperDARN speeds are consistently less than speeds obtained by other instruments, such as DMSP [Drayton et al., 2005; Drayton, 2006], the European Incoherent SCATter radar (EISCAT) [Davies et al., 1999], and the Canadian Advanced Digital Ionosonde (CADI) [Xu et al., 2001; $X u, 2003]$. Including the index of refraction term, as required by equation (2), in the SuperDARN determination of velocity is not possible unless there is a reliable $n_{s}$ estimation for a given observation. It is important to include refractive index effects in the velocity determinations since SuperDARN is an important instrument for ionospheric and magnetospheric studies. SuperDARN produces large-scale convection maps and associated cross polar cap potential difference values every 1 or $2 \mathrm{~min}$. The data products that are based on the SuperDARN observations may therefore also be not as accurate as they could be. In addition to radar studies of the ionosphere, SuperDARN provides important content to a number of multi-instrument collaborations, such as CLUSTER [Balogh et al., 2001] and THEMIS [Angelopoulos, 2008] studies, so it is prudent to find a method to estimate $n_{s}$.

[3] The parameters which determine the index of refraction in an ionized magnetic medium are given in the Appleton-Hartree equation [Budden, 1961]; mainly, the electron concentration (number density) $N_{e}$, the magnetic field vector, and the radar wave frequency. In the $F$ region ionosphere the controlling parameters are $N_{e}$ and the radar wave frequency. The peak electron concentration in the $F$ region ionosphere ranges typically from $10^{11} \mathrm{~m}^{-3}$ to $10^{12} \mathrm{~m}^{-3}$ [e.g., Hunsucker and Hargreaves, 2003]. With this range of possible number densities, and for SuperDARN HF frequencies in the range $9-18 \mathrm{MHz}, n_{s}$ can vary from $\sim 0.0$ to 1.0 , but, as will be shown below, typical values appear to be between 0.8 and 1.0.

\section{Ray Path Modeling}

[4] Ray tracing equations as derived by Haselgrove [1963], and based on the Appleton-Hartree equation for the index of refraction, have been modeled in a computer program. The model has been used to calculate the path an HF radar wave will travel through a magnetized plasma, such as the ionosphere. Magnetic field information for the ray tracing model is supplied by the International Geomagnetic Reference Field (IGRF) model [Maus et al., 2005]. An electron density profile is user supplied and can be one- or two-dimensional. The 1-D profiles vary with altitude only and thus maintain the same profile at all horizontal (or latitudinal) distances. The 2-D profiles vary with latitude, as well as with altitude.

\subsection{Refraction in a Spherical Coordinate System}

[5] If the ionosphere is assumed to be a collection of spherical shells concentric with the center of the Earth, one can utilize Bouguer's law [Born and Wolf, 1959], which is Snell's law applied to a spherical coordinate system, to obtain an expression relating the index of refraction at the scattering volume to the angle of arrival or the elevation angle of a backscattered radar wave

$$
n R \cos \phi=n_{o} R_{o} \cos \phi_{o}
$$

The variables $n_{o}, R_{o}$, and $\phi_{o}$ are the initial refractive index, radius (from the center of the Earth), and elevation angle of the ray, respectively, and $n, R, \phi$ have similar meaning except at some arbitrary point along the raypath. In the case of scatter from field-aligned irregularities using SuperDARN, these quantities are all relatively well known. First, replace the arbitrary $n$ value with $n_{s}$ to represent the index of refraction at the scattering location. The initial radius, $R_{o}$, is the radius of the Earth. The final radius $R$ is the radius of the Earth plus the scattering altitude $\left(h_{s}\right)$. The angle of arrival $\phi_{o}$ is known from interferometry measurements performed by SuperDARN [Milan et al., 1997; André et al., 1998]. The final elevation angle $\phi$ is $90^{\circ}$ minus the magnetic dip angle $\psi$ for scattering from field-aligned irregularities. Rearranging equation (3) to determine $n_{s}$ in the scattering region gives

$$
n_{s}=\frac{R_{E}}{\left(R_{E}+h_{s}\right)} \frac{\cos \phi_{o}}{\sin \psi} .
$$

Equation (4) is independent of any vertical gradients in electron concentration $N_{e}$ (or consequently the index of refraction $n$ ) along the raypath. Both $\psi$ and $h_{s}$ in equation (4) have some variability; however, as will be demonstrated in section 3.1 , any variation of $\psi$ between $80^{\circ}$ and $90^{\circ}$ or $h_{s}$ between $150 \mathrm{~km}$ and $400 \mathrm{~km}$ (which are appropriate values for high-latitude $F$ region coherent backscatter) will have a limited effect on the value of $n_{s}$. Therefore, the only piece of information that is needed to determine $n_{s}$ (and thus determine a refined measured Doppler velocity) is the elevation angle of the returned radar wave. It must be noted, however, that horizontal gradients in $N_{e}$ were not taken into account in the derivation of equation (4). In order to determine the effect of horizontal gradients on $n_{s}$, raypath modeling has been performed.

\subsection{Electron Density Profile Selection}

[6] To cover the range of possible propagation conditions, a total of 43 different electron number density profiles have been used for the raypath modeling in this study. Of these profiles, twenty were horizontally stratified with $N_{e}$ only varying in altitude. These 1-D profiles were generated using the International Reference Ionosphere (IRI) model [Bilitza, 2001] for both day and night conditions with peak electron concentrations ranging from $10^{11} \mathrm{~m}^{-3}$ to $10^{12} \mathrm{~m}^{-3}$. In addition to this, $232-\mathrm{D}$ profiles were also created with $N_{e}$ varying with latitude and altitude (only latitudinal horizontal gradients were considered in the present study). These 2-D profiles were categorized as follows: (1) eight were based on ISIS II topside sounding measurements [Bilitza et al., 2004]; (2) three were directly generated from the IRI model; (3) eight were based on midlatitude trough measurements [Kersley et al., 1997; Moffett and Quegan, 1983]; (4) four were artificial profiles with exceptionally large horizontal gradients. An example of one of the 2-D profiles is presented as Figure 1. This $N_{e}$ profile was generated using both the IRI model and ISIS II topside sounding measurements from 27 June 1978.

[7] The objective for creating these 2-D profiles was to simulate a variety of expected profiles based on observed data as well as some profiles with extreme horizontal gradients which would not be normally expected. The 


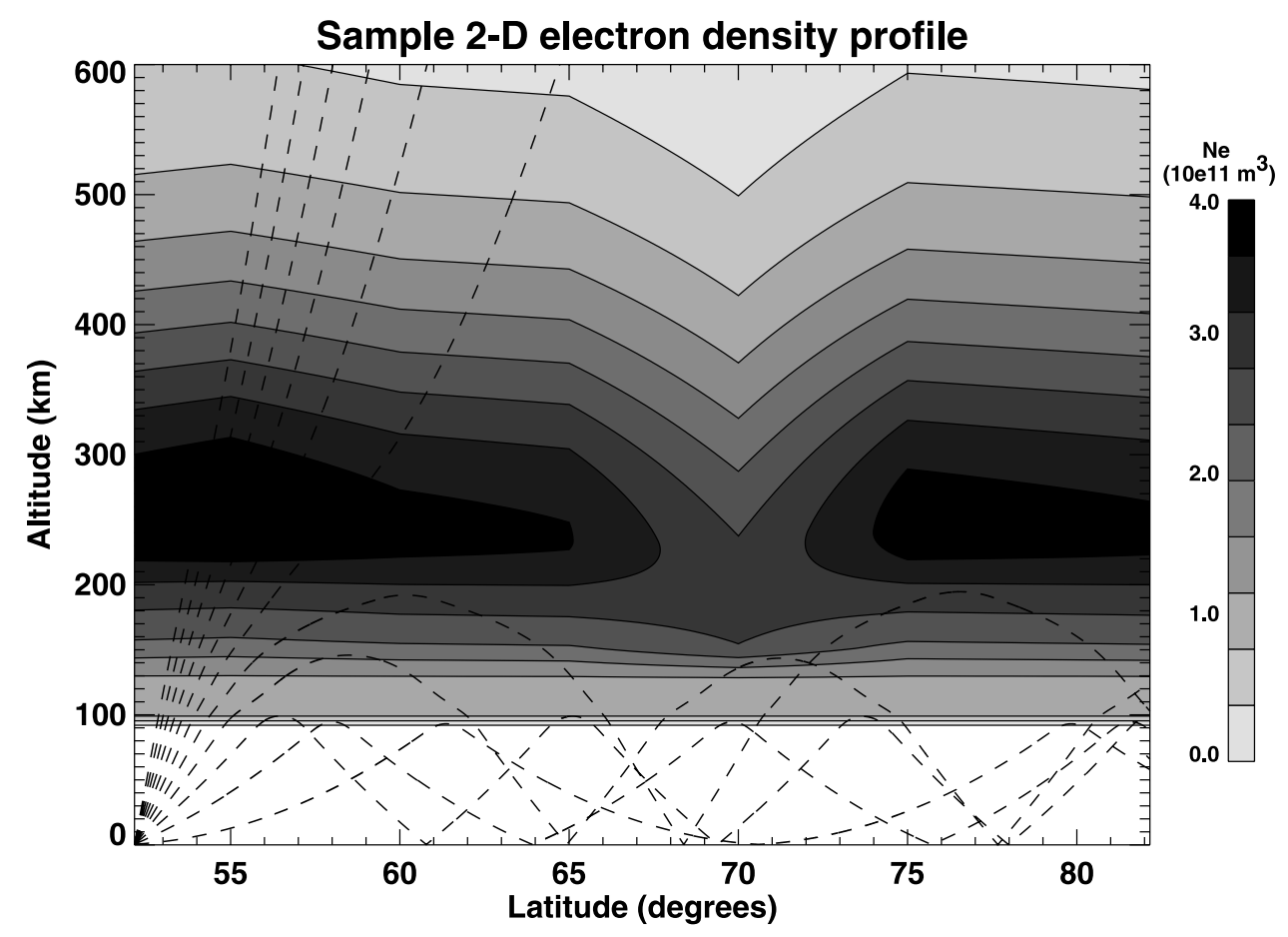

Figure 1. A sample of an electron density profile that was used in this study. The electron density profile was determined using both ISIS II topside soundings of the $f_{o} F_{2}$ peak on 27 June 1978 and the IRI model. The dashed lines on the plot represent a sampling of raypaths from the Saskatoon SuperDARN at a transmitter frequency of $12.5 \mathrm{MHz}$ for varying elevation angles.

profiles constructed to have extreme horizontal gradients had peak electron density gradients of $0.5 \times 10^{11} \mathrm{~m}^{-3} /{ }^{\circ}$ lat over $20^{\circ}$ latitude, which is larger than the expected gradient over this latitudinal range from the change in solar zenith angle. In the trough modeled profiles, the peak latitudinal electron density gradient reached $2 \times 10^{11} \mathrm{~m}^{-3} /{ }^{\circ}$ lat, although the horizontal gradient was more localized in latitude. Smaller-scale horizontal gradients, such as the strong gradients associated with precipitation events were not considered.

\section{Results}

\subsection{Elevation Angle Dependence}

[8] The ray tracing program was used to calculate the path that a radar wave at a given elevation angle would travel through modeled $N_{e}$ profiles. Radar wave paths for integer values of elevation angles from $1^{\circ}$ to $90^{\circ}$ were simulated at three frequencies $(9.5 \mathrm{MHz}, 12.5 \mathrm{MHz}$, and 14.5 MHz) for each of the 43 profiles discussed in section 2.2. The points on the raypaths where the ray was within $1^{\circ}$ of perpendicularity to the magnetic field lines were selected as scattering locations and recorded, along with the refractive index and elevation angle, subject to the restriction that only scattering heights above an altitude of $150 \mathrm{~km}$ were appropriate for $F$ region scatter.

[9] According to equation (4), there should be a clear relationship between the received elevation angle and the refractive index for a spherically stratified ionosphere. The primary objective of the ray tracing simulations was to determine the effect of horizontal gradients on this relationship. Scatter plots of $\phi_{o}$ versus $n_{s}$ (elevation angle versus index of refraction at the scattering location) derived from the simulations are presented as Figure 2. Also included in each plot, as two thick dashed lines, are the conceptual curves from equation (4) for both $h_{s}=150 \mathrm{~km}, \psi=80^{\circ}$ and $h_{s}=400 \mathrm{~km}, \psi=90^{\circ}$. Note that these extremes in assumed magnetic dip angle and scatter altitude only change the analytical curve to a minimal degree. The scatter points are split into two groups, those obtained using 1-D electron density profiles (Figure 2a) and those using 2-D electron density profiles (Figure 2b). The points from the 1-D profiles follow the conceptual curves closely as is expected, while the points from the 2-D profiles deviate slightly from the curves.

[10] Figure 2 clearly illustrates the relationship between angle of arrival and refractive index. There is some deviation from the Bouguer's law due to the profiles with the simulated extreme horizontal gradients, but the points generally follow the expected curve. From these plots it is apparent that the measured angle of arrival $\phi_{o}$ of a SuperDARN echo leads to a reasonable estimate of the local index of refraction $n_{s}$ in the scattering region. This allows for the inclusion of $n_{s}$ in the measured Doppler velocity calculation to be made.

[11] A SuperDARN radar measures elevation angle by using a receiving-only interferometry array of 4 antennas positioned behind or in front of the main array by $\sim 100 \mathrm{~m}$. The cross-correlation between the signal received by the interferometry array and the main array is used to determine the phase difference and elevation angle of the returned echo [Milan et al., 1997; André et al., 1998]. A point of consideration, however, is that the SuperDARN interferometer array can only unambiguously measure elevation angles 

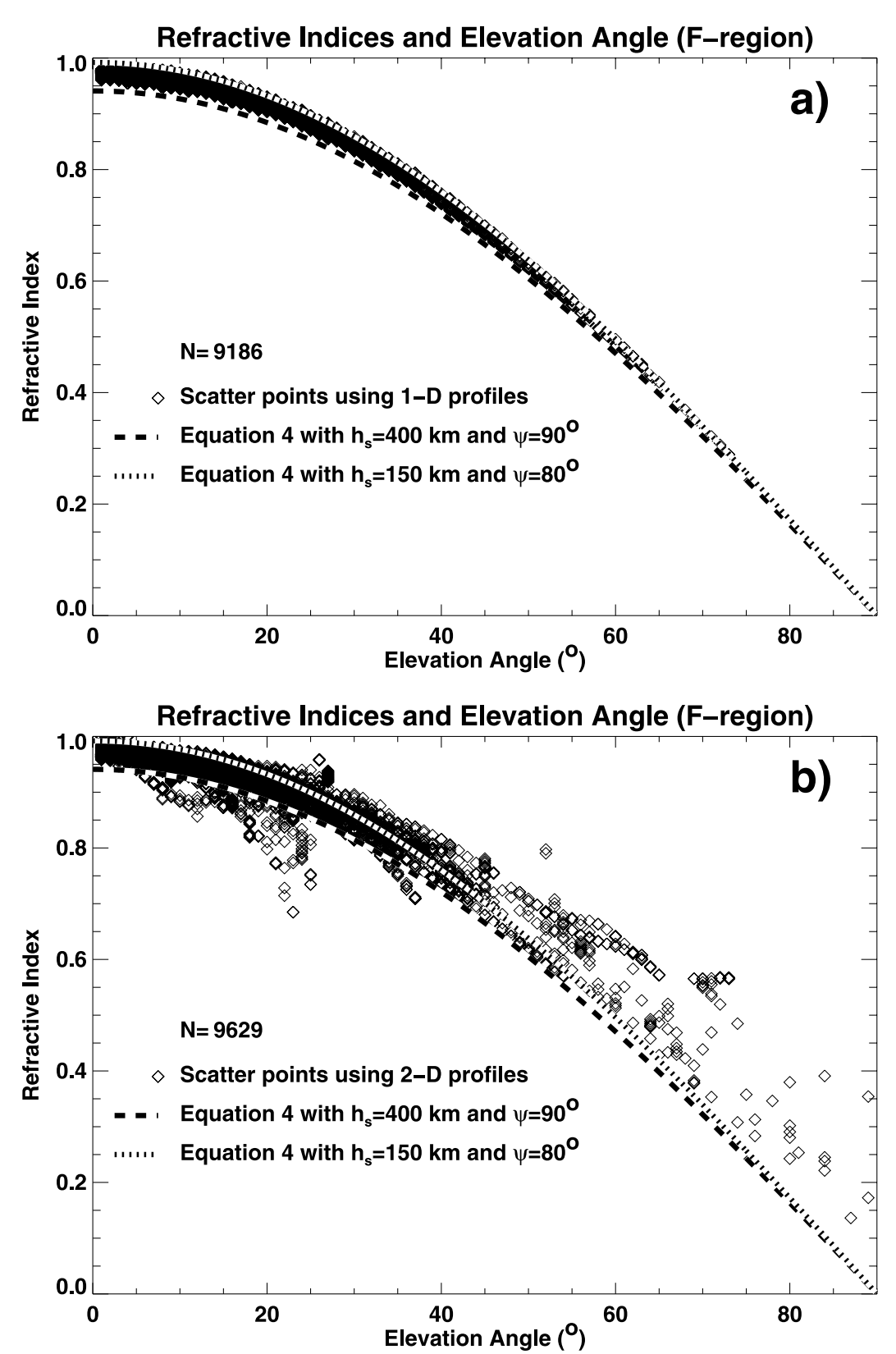

Figure 2. Indices of refraction and elevation angles from ray trace modeling in the $F$ region. Each point represents a point on a ray that was within $1^{\circ}$ of perfect aspect and was above $150 \mathrm{~km}$ altitude. (a) Scatter points found using 1-D $N_{e}$ profiles and (b) scatter points found using 2-D $N_{e}$ profiles. The two conceptual curves in each plot are found using equation (4) for two different values of scattering altitude and magnetic dip angle.

if they are less than $\phi_{\text {lim }} \sim 40^{\circ}$, the exact angle being dependent on frequency. This is because the phase difference between the main array and the interferometry array can only be measured up to modulo $2 \pi$. Any echoes that occur at elevation angles greater than $\phi_{\text {lim }}$ will be recorded as lower elevation angles. However, as shown in section 3.2, very few modeled scattering points have elevation angles above this value and this restriction should therefore typically not be a concern.

\subsection{Scattering Statistics}

[12] Although the points presented in Figure 2 are all the result of computational modeling, it is of interest to examine the statistical variation of the refractive index. It should be noted that the actual $N_{e}$ profiles are not known accurately along the SuperDARN raypaths. The profiles used were chosen to examine the range of possible combinations that might occur. Neither ionosonde observations nor TEC profiles, such as those from GPS receiver arrays, can provide sufficient resolution and detail. An RRI (Radio Receiver Instrument) experiment in which actual SuperDARN transmissions are received every $\sim 20 \mu$ s along the ePOP satellite trajectory may provide more detailed $N_{e}$ profiles [Yau et al., 2006]. The occurrence of index of refraction in the simulated scattering region above $150 \mathrm{~km}$ are presented in Figure 3. From Figure 3 it is apparent that, 


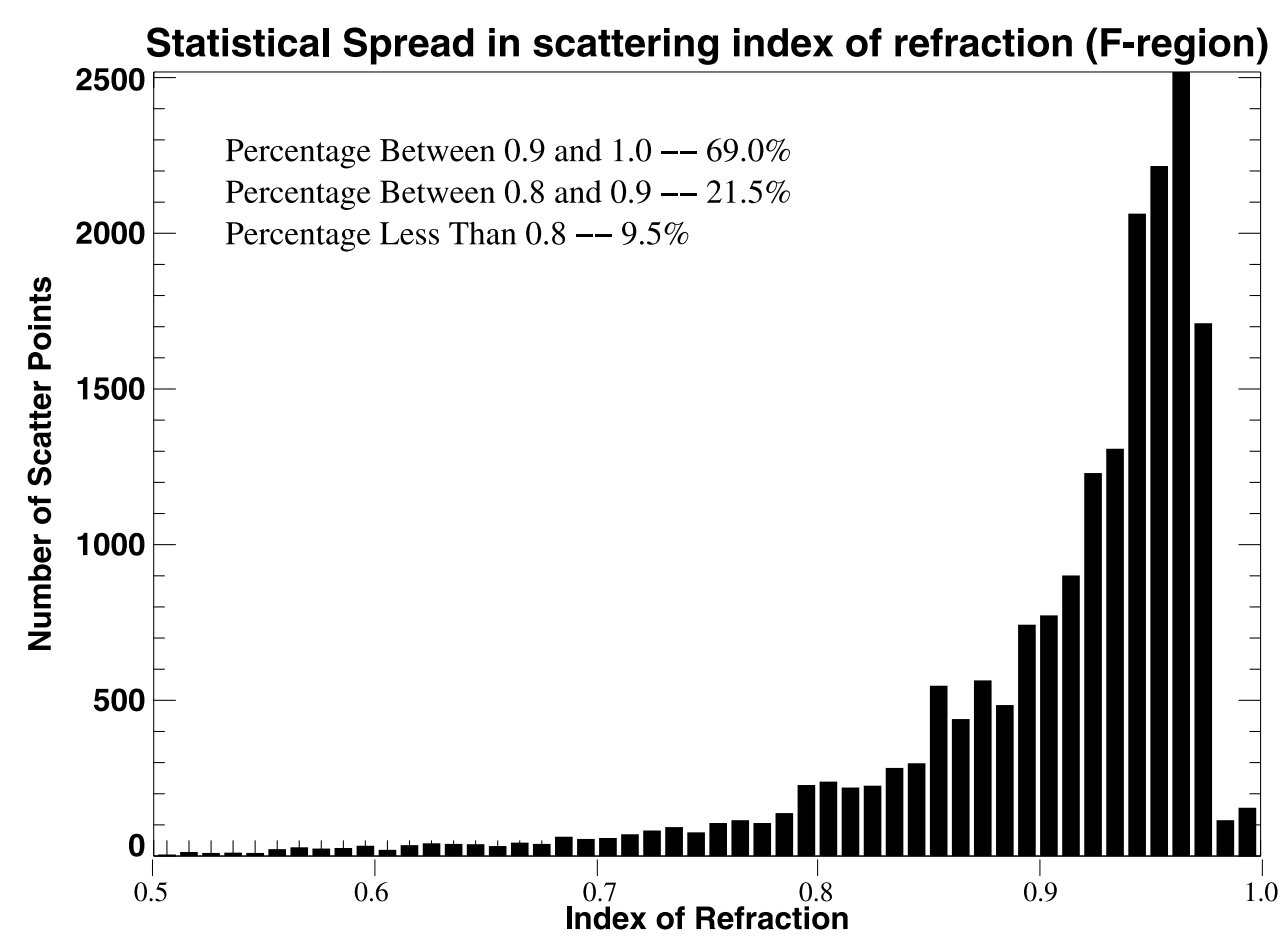

Figure 3. Statistical variation of index of refraction derived from the simulations in the scattering region for scattering altitudes above $150 \mathrm{~km}$.

for the profiles simulated in this study, the majority $(\sim 70 \%)$ of refractive index values in the scattering region are $>0.9$. Only about $20 \%$ of the echoes have a refractive index between 0.8 and 0.9 , and less than $10 \%$ have an index of refraction $<0.8$. The weighted mean value for $n_{s}$ is 0.91 . This suggests that even if the refractive index cannot be estimated using angle-of-arrival measurements (e.g., owing to lack of interferometry measurements), the SuperDARN measured Doppler velocity for a given ionospheric echo is typically around $10 \%$ too low.

\subsection{DMSP/SuperDARN Velocity Comparison}

[13] There have been a number of previous comparisons of $F$ region velocity measurements between SuperDARN and a variety of other instruments. For example, Davies et al. [1999] compared SuperDARN velocities with velocities from the EISCAT incoherent scatter radar, Xu et al. [2001] compared SuperDARN velocities with velocities from the Sondrestrom incoherent scatter radar, and $X u$ [2003] compared SuperDARN velocities with velocities obtained from ionosondes, incoherent scatter radars, and DMSP satellites. Drayton [2006] and Drayton et al. [2005] performed an extensive comparison between SuperDARN and DMSP velocities. Data over a 4 year period (1999-2002) were compared when the satellite and radar velocity components were within $5^{\circ}$. A least squares fit of the velocity measurements between SuperDARN and DMSP gave a slope of 0.84 in the Drayton [2006] study.

[14] As a test to see if including the refractive index correction at the scattering region in the SuperDARN velocity calculations eliminates, or at least reduces, the apparent underestimation of SuperDARN velocity measurements, another SuperDARN-DMSP comparison was performed for this paper (other comparisons are in progress).
The Drayton [2006] study was used as a basis for applying the $n_{s}$ refinement to SuperDARN Doppler velocity calculations. In this present comparison, the proxy method to obtain an estimate of the refractive index at the scattering region by using the angle of arrival or elevation angle of the returned echo (equation (4)), was employed. The refractive index term has been omitted from the SuperDARN velocity calculation in the past because the value was unknown. Unfortunately, some of the radars in the Drayton [2006] study did not have elevation angle data available. Therefore, the inclusion of the $n_{s}$ term to the entire data set was not possible and $\sim 80 \%$ of the data points which they employed had to be discarded, leaving 159 individual velocity comparisons to consider.

[15] The possibility of including SuperDARN scatter from the $E$ region of the ionosphere, where the drift velocity is not expected to be equivalent to the ExB velocity was taken into consideration. As an initial check, trigonometry was employed, including multiple hop scenarios, using the measured elevation angle of an echo and the slant range to estimate the altitude of the ionospheric scatter. It was found that only ten of the 159 measurements which were considered in this study had the slightest possibility of being from an altitude appropriate for $E$ region scatter. As a final check, these possible $E$ region echoes were found not to have significantly lower SuperDARN velocity values than the corresponding DMSP measurements. Therefore, there was no $E$ region contamination.

[16] The selection criteria for DMSP and SuperDARN velocity values to compare was covered in detail by Drayton et al. [2005]; however, a brief summary is presented in this paper. SuperDARN line-of-sight data collected in the standard mode of operation with 1 or 2 min scan times was considered. In these modes each of 


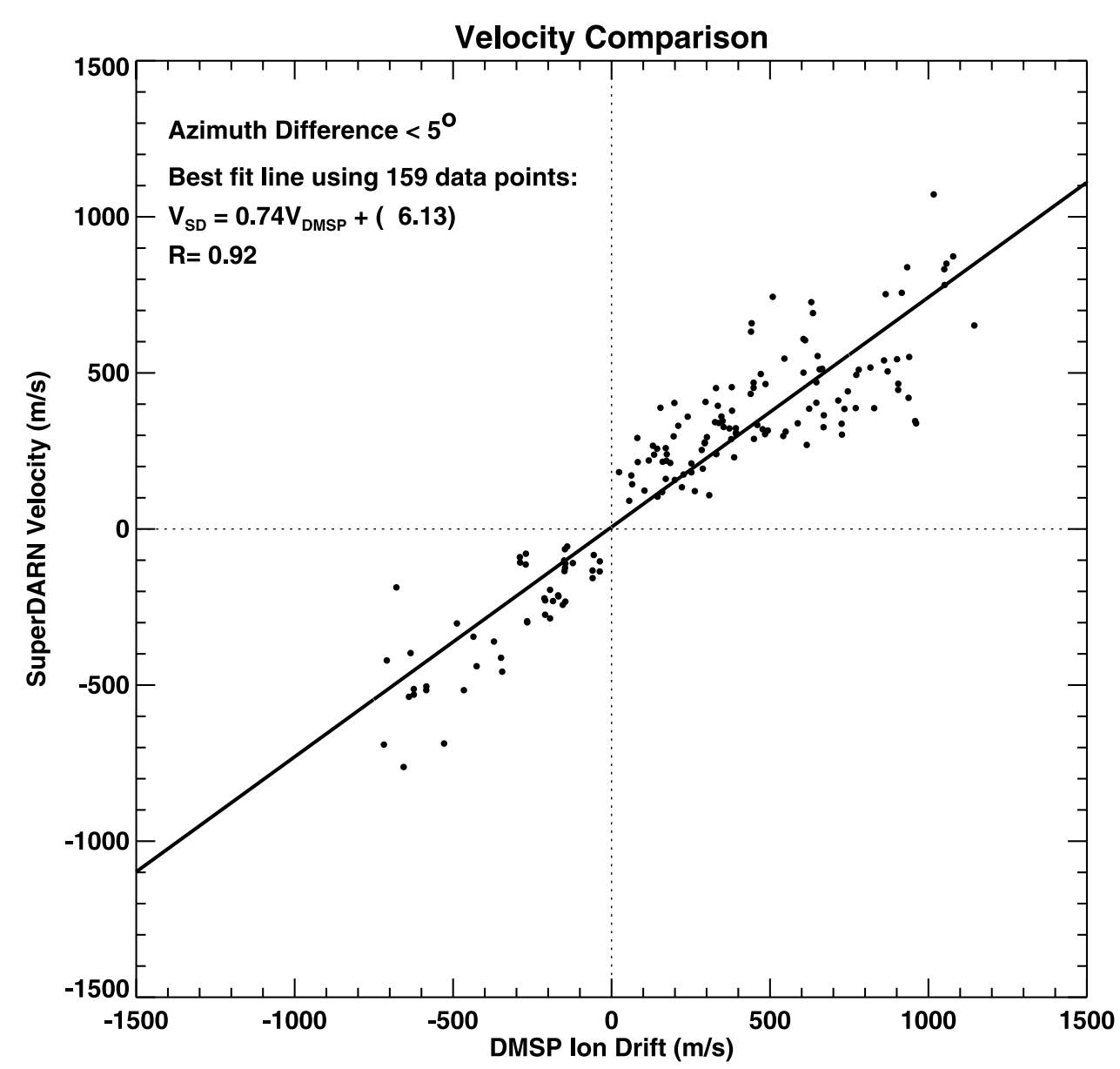

Figure 4. SuperDARN and DMSP velocity comparison. The data have been corrected for the field mapping between $840 \mathrm{~km}$ (DMSP altitude) and $250 \mathrm{~km}$ (SuperDARN scatter altitude). The solid line represents the least squares best fit.

the 16 beams of a given radar was scanned for either 3 or $7 \mathrm{~s}$ (1 min or 2 min scans, respectively). The beam width was $3.24^{\circ}$, corresponding to a cell width of $\sim 110 \mathrm{~km}$ at a range of $2000 \mathrm{~km}$, which was the average range. The velocity measurements were binned into $45-\mathrm{km}$ range gates beginning at $180 \mathrm{~km}$. Only SuperDARN velocities with echo power of more than $3 \mathrm{~dB}$ and a spectral width of less than $500 \mathrm{~m} / \mathrm{s}$ were considered.

[17] The DMSP data consisted of 4-s averaged crosstrack ion drift measurements. Measurements with a poor quality flag were not considered. Satellite passes over a given radar were considered if the angle between the crosstrack ion drift measurement of the satellite and the line-ofsight measurement of the radar in the horizontal plane were within $5^{\circ}$. All 4-s DMSP measurements which were within $45 \mathrm{~km}$ of the center of the SuperDARN cell of interest were averaged. Usually three DMSP measurements met this criteria for a given SuperDARN range cell. This averaging resulted in a DMSP measurement over about $90 \mathrm{~km}$ along the satellite track compared to the $\sim 45 \times 110-\mathrm{km}$ SuperDARN cell. The DMSP velocity measurement at $\sim 840 \mathrm{~km}$ was then mapped down to the SuperDARN measurement altitude of $\sim 250 \mathrm{~km}$. Measurements of DMSP were recorded if they met the previous criteria and occurred within the 1 or 2 min scan time of the given SuperDARN radar. Therefore, measurement times may have been separated by up to $2 \mathrm{~min}$; however, the actual integration time by each instrument was comparable $(\sim 12$ s for DMSP and 3 or $7 \mathrm{~s}$ by SuperDARN).

[18] The comparison between DMSP and SuperDARN velocities when elevation angle information was available is presented as Figure 4. A linear regression analysis of the data found that the slope of the best fit line was 0.74 and the regression coefficient was 0.92 . This comparison includes an altitude ExB correction along dipole field lines. A dipole field-mapping correction to velocities accounts for the difference in measurement altitude of $\sim 840 \mathrm{~km}$ altitude for DMSP and an assumed scattering altitude of $250 \mathrm{~km}$ for SuperDARN. This altitude difference results in the higheraltitude measurements being $\sim 16 \%$ larger before being mapped down to SuperDARN scattering altitudes [Drayton, 2006]. Again, the comparison shows that SuperDARN velocities were on average lower than DMSP values, and, in fact, even lower than the Drayton [2006] study where the slope of the best fit line was 0.84 . The discrepancy between these two data sets is addressed in section 3.3.1.

[19] The index of refraction proxy using elevation angle was used to improve the velocity measurements for SuperDARN. In Figure 5, the comparison data is presented with the SuperDARN velocity calculations improved using the 


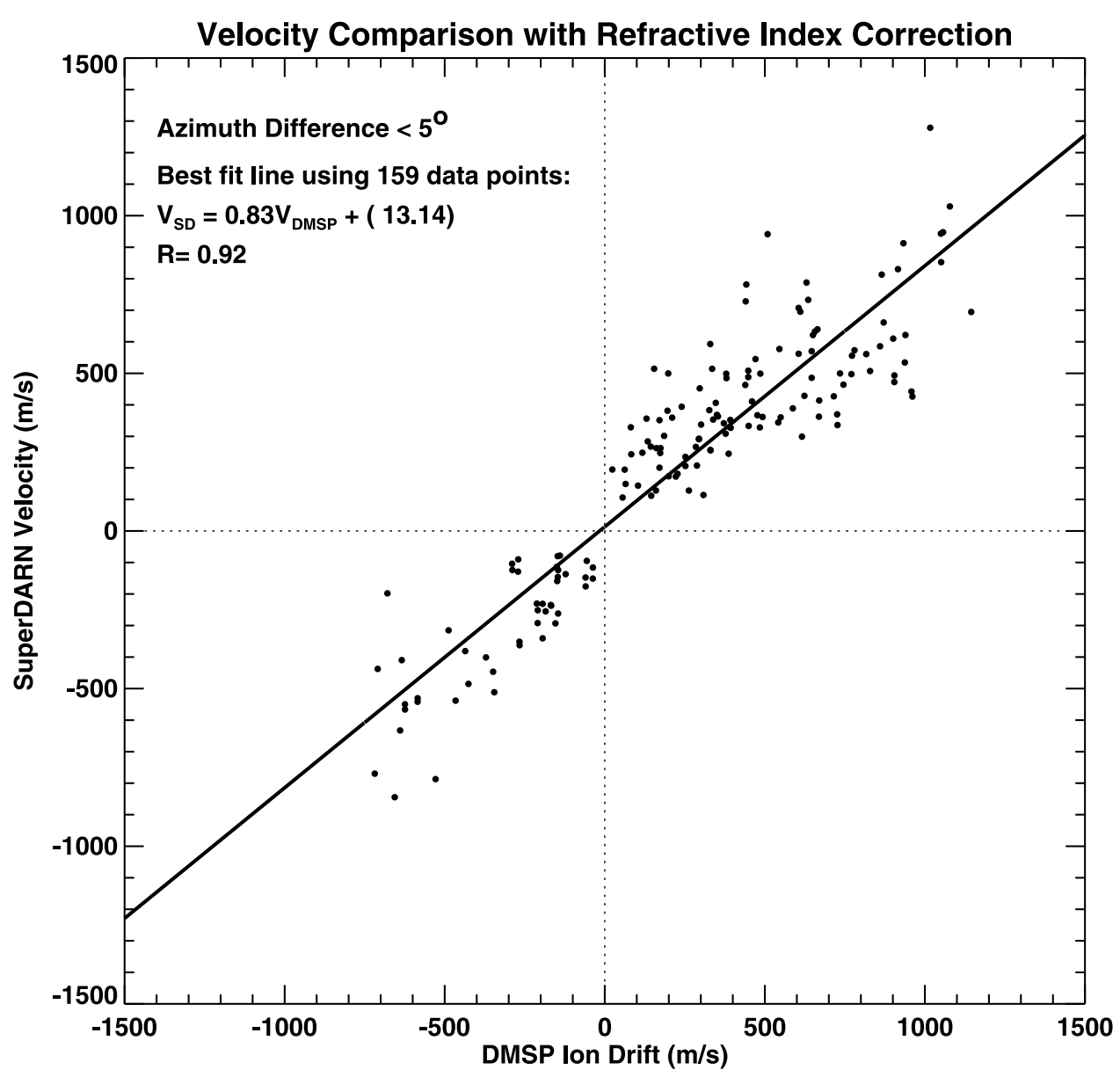

Figure 5. SuperDARN and DMSP velocity comparison. The data have been corrected for both the field mapping between $840 \mathrm{~km}$ (DMSP altitude) and $250 \mathrm{~km}$ (SuperDARN scatter altitude) and the index of refraction using equation (4) with SuperDARN angle-of-arrival data. The solid line represents the least squares best fit.

elevation angle as a proxy to provide an index of refraction estimate from equation (4). For this estimate of $n_{s}$, the scattering altitude was assumed to be $h_{s}=250 \mathrm{~km}$ and $\psi$ was found using a dipole estimate for the magnetic field of the Earth (note that $\psi$ was always between $80^{\circ}$ and $90^{\circ}$ and therefore was essentially constant). There is better agreement between the velocity measurements of the two instruments, with the slope of the best fit line increasing from 0.74 to 0.83 .

\subsubsection{Examination of Slope Difference}

[20] The difference in slope between the Drayton [2006] study $(0.84)$ and the subset of the data used in this study (0.74) is quite large. The discrepancy between the data sets is a systematic effect because repeatedly randomly sampling $20 \%$ of the points from the Drayton [2006] study could not produce a slope as low as 0.74 .

[21] A probable explanation for the lower slope velocity comparison value in the present study compared to the slope in the Drayton [2006] study is that the radars which provided the elevation angle data in this study had relatively more data points within the auroral oval than the Drayton [2006] study. Table 1 lists the radars used in both studies, the number of data points used for each, and the slope values obtained.
[22] The number of data points inside and outside the auroral oval were determined using DMSP particle spectra to estimate the location of the auroral oval. It was found that for the Drayton [2006] study, 244 out of 715 points were within the oval $(\sim 34 \%)$, while for the subset of points in which elevation angle data was available for this study, 101 out of 159 points were within the oval $(\sim 64 \%)$. A linear regression analysis of the points within the auroral oval results in a best fit slope of 0.71 , while the same analysis of points outside the auroral oval results in a best fit slope of

Table 1. SuperDARN Radars Used for Velocity Comparisons

\begin{tabular}{lcccccc}
\hline & \multicolumn{2}{c}{ Drayton [2006] } & & \multicolumn{2}{c}{ Present Study } \\
\cline { 2 - 3 } \multicolumn{1}{c}{ Radar } & $\begin{array}{c}\text { Number of } \\
\text { Points }\end{array}$ & $\begin{array}{c}\text { Best Fit } \\
\text { Slope }\end{array}$ & & $\begin{array}{c}\text { Number of } \\
\text { Points }\end{array}$ & $\begin{array}{c}\text { Best Fit } \\
\text { Slope }\end{array}$ \\
\hline Halley & 159 & 0.58 & & 0 & - \\
Hankasalmi & 43 & 0.74 & & 27 & 0.81 \\
Kodiak & 111 & 0.87 & & 37 & 0.82 \\
Pykkvibaer & 60 & 0.71 & & 51 & 0.72 \\
Sanae & 80 & 0.56 & & 0 & - \\
Saskatoon & 59 & 0.68 & & 43 & 0.70 \\
Stokkseyri & 49 & 0.87 & & 1 & - \\
Syowa East & 86 & 0.99 & & 0 & - \\
Syowa South & 68 & 0.90 & & 0 & - \\
\hline
\end{tabular}


0.86. Clearly, the points within the auroral oval (which the subset used in this study is biased toward) had a tendency to have a lower best fit slope value than the points outside the auroral oval.

[23] One possible explanation for this difference is that higher electron densities within the auroral oval produce a lower index of refraction, on average. Higher electron densities in the auroral zone are expected for a number of reasons. Within the auroral oval, processes such as particle precipitation, field aligned currents, and higher photoionization could all cause the electron density to increase, particularly in the scattering regions where highly structured and large $N_{e}$ spatial gradients are expected in the neighborhood of small-scale, intense FACs whose primary precipitating electrons produce large numbers of secondary electrons. This would reduce the index of refraction. If this reduction is neglected, the result is lower SuperDARN velocity measurements and a lower slope when compared with DMSP measurements. It is also likely that the greatest contributions to the radar scattering are the areas where the electron densities and their gradients are the most extreme.

[24] In contrast, in the polar cap region where there is less photoionization and the plasma density becomes depleted because of the polar wind and diffusion on open flux tubes, the electron densities are expected to be lower, on average. Therefore the index of refraction is expected to be closer to unity, so the measured SuperDARN velocities there should be closer to the values obtained from DMSP.

\section{Discussion}

[25] SuperDARN velocity measurements are routinely calculated using equation (1), which does not account for the refractive index in the scattering region. To account for $n_{s}$, equation (2) should be employed; however, a measured estimate of $n_{s}$ was not available until now. The use of equation (4) and the interferometry measured elevation angle is able to give a proxy for an estimate of $n_{s}$ which allows the use of equation (2) for a better velocity estimate by SuperDARN. As equation (4) was derived under spherically symmetric conditions, horizontal gradients were not taken into account. Section 3 was concerned with accessing the significance of these horizontal gradients in using equation (4) as a proxy estimate of $n_{s}$. This analytical proxy showed that the presence of horizontal gradients caused some deviation from equation (4), as would be expected; however, use of equation (4) is an excellent zeroth-order estimate for $n_{s}$, the index of refraction in the scattering region.

[26] Figure 5 illustrates that SuperDARN velocity measurements appear to be systematically underestimated when compared to DMSP even after taking into consideration $n_{s}$ using the elevation angle proxy. One possible reason for this discrepancy may arise from temporal and spatial disagreement between measurements. In both this and the Drayton [2006] studies, although both the integration time and spatial extent of measurements were comparable, they may have occurred up to $2 \mathrm{~min}$ apart and the refractive nature of SuperDARN HF wave propagation could also have caused a small uncertainty in determination of the scattering location. On a statistical basis, however, these sources of disagreement should tend to cancel out (i.e.,
SuperDARN should both overestimate and underestimate some velocities). This does not appear to be the case here and would also not explain previous comparisons with other instruments in which SuperDARN velocities were always statistically lower.

[27] The modeling in this study has been focused on large-scale effects of horizontal gradients on the elevation angle proxy for estimating $n_{s}$, and did not consider the much smaller scale, but potentially high gradients, expected to be present (and required) for scattering. Such gradients would be expected to be present as there is auroral precipitation in this region which would cause gradient structures as small as hundreds of meters or even less to develop [e.g., Noël et al., 2000, 2005; Sofko et al., 2007]. Furthermore, mediumscale structures, such as polar patches would also cause deviation from the analytical curve. In fact, it may be that ionospheric scatter occurs predominantly in the presence of such density gradients. One of the main sources of ionospheric irregularities that cause coherent scatter is the gradient drift instability, which requires gradients in electron density. As scattering is assumed to occur predominantly in the presence of such structures, then the few points clustered below the analytical curve in Figure 2 (which were the result of raypath modeling using high electron density gradients) may occur more often than the modeling suggests. Inclusion of these potentially important effects requires further study.

\section{Conclusions}

[28] The index of refraction in the SuperDARN scattering region has been neglected in velocity estimations until now as it was not typically available. This has resulted in underestimation of measured Doppler velocities by SuperDARN. As these measurements can be an integral part of studies in ionospheric and magnetospheric science any improvements in their accuracy is beneficial.

[29] This paper presents a method to obtain a refinement to SuperDARN velocities by using angle-of-arrival or elevation angle measurements of the returned radar echoes as a proxy for the index of refraction in the scattering volume. Evidence supporting the proposed relation between angle of arrival and index of refraction was provided by raypath modeling. Ray tracing simulations through a variety of 1-D and 2-D ionospheric electron density profiles have indicated that the index of refraction in the scattering region is usually between 0.8 and 1.0 for $\sim 90 \%$ of cases. To further test the proxy, a velocity comparison between DMSP and SuperDARN measurements has also been performed. This study found that the comparison between SuperDARN and DMSP measured velocities was improved by inclusion of the index of refraction using elevation angle data; however, SuperDARN measured velocities were still lower on average. Nevertheless, the elevation angle method to determine a proxy for index of refraction is a simple, but effective, first step toward improving SuperDARN velocity measurements.

[30] Acknowledgments. We acknowledge the support of the Canadian Space Agency and the Natural Sciences and Engineering Research Council (NSERC) to the Canadian component of the SuperDARN groundbased radar system and the CASSIOPE/ePOP project for our research. International Reference Ionosphere (IRI) electron density profiles have been 
provided by the Space Physics Data Facility (SPDF). Digitized online ISIS II data have been supplied by R. F. Benson at the National Aeronautics and Space Administration (NASA) Goddard Space Flight Center (GSFC) and Coordinated Data Analysis Web (CDAWeb). We gratefully acknowledge the Center for Space Sciences at the University of Texas at Dallas and the U.S. Air Force for providing the DMSP thermal plasma data.

[31] Zuyin Pu thanks Ray Greenwald and Darren Wright for their assistance in evaluating this paper.

\section{References}

André, D., G. Sofko, K. Baker, and J. MacDougall (1998), SuperDARN interferometry: Meteor echoes and electron densities from groundscatter, J. Geophys. Res., 103, 7003-7015.

Angelopoulos, V. (2008), The THEMIS Mission, Space Sci. Rev., 141, $5-34$.

Baker, K. B., J. R. Dudeney, R. A. Greenwald, M. Pinnick, P. T. Newell, A. S. Rodger, N. Mattin, and C.-I. Meng (1995), HF radar signatures of the cusp and low-latitude boundary layer, J. Geophys. Res., 100, 76717695.

Balogh, A., et al. (2001), The Cluster Magnetic Field Investigation: Overview of in-flight performance and initial results, Ann. Geophys., 19, $1207-1217$.

Bilitza, D. (2001), International Reference Ionosphere 2000, Radio Sci., 36, $261-275$.

Bilitza, D., X. Huang, B. W. Reinisch, R. F. Benson, H. K. Hills, and W. B. Schar (2004), Topside Ionogram Scaler With True Height Algorithm (TOPIST): Automated processing of ISIS topside ionograms, Radio Sci., 39, RS1S27, doi:10.1029/2002RS002840.

Born, M., and E. Wolf (1959), Principles of Optics: Electromagnetic Theory of Propagation, Interference and Diffraction of Light, Pergamon, New York.

Budden, K. G. (1961), Radio Waves in the Ionosphere, Cambridge Univ. Press, Cambridge, U. K.

Davies, J. A., M. Lester, S. E. Milan, and T. K. Yeoman (1999), A comparison of velocity measurements from the CUTLASS Finland radar and the EISCAT UHF system, Ann. Geophys., 17, 892-903.

Drayton, R. A. (2006), Study of SAPS-like flows with the King Salmon SuperDARN radar, M.Sc. thesis, Univ. of Saskatchewan, Saskatoon, Saskatchewan, Canada.

Drayton, R. A., A. V. Koustov, M. R. Hairston, and J.-P. Villian (2005), Comparison of DMSP cross-track ion drifts and SuperDARN line-ofsight velocities, Ann. Geophys., 23, 2479-2489.

Ginzburg, V. L. (1964), The Propagation of Electromagnetic Waves in Plasmas, Pergamon, New York.
Greenwald, R. A., et al. (1995), DARN/SuperDARN: A global view of the dynamics of high-latitude convection, Space Sci. Rev., 71, 761-796.

Haselgrove, J. (1963), The Hamiltonian ray path equations, J. Atmos. Terr. Phys., 25, 397-399.

Hunsucker, R. D., and J. K. Hargreaves (2003), The High-Latitude Ionosphere and Its Effects on Radio Propagation, Cambridge Univ. Press, Cambridge, U. K.

Kersley, L., S. E. Pryse, I. K. Walker, J. A. T. Heaton, C. N. Mitchell, M. J. Williams, and C. A. Willson (1997), Imaging of electron density troughs by tomographic techniques, Radio Sci., 32(4), 1607-1621.

Maus, S., et al. (2005), The 10th generation international geomagnetic reference field, Phys. Earth Planet. Inter., 151, 320-322.

Milan, S. E., T. B. Jones, T. R. Robinson, E. C. Thomas, and T. K. Yeoman (1997), Interferometric evidence for the observation of ground backscatter originating behind the CUTLASS coherent radars, Ann. Geophys., 15, $29-39$.

Moffett, R. J., and S. Quegan (1983), The mid-latitude trough in the electron concentration of the ionospheric F-layer: A review of observations and modelling, J. Atmos. Terr. Phys., 45(5), 315-343.

Noël, J.-M. A., J.-P. St.-Maurice, and P.-L. Blelly (2000), Nonlinear model of short-scale electrodynamics in the auroral ionosphere, Ann. Geophys., $18,1128-1144$

Noël, J.-M. A., J.-P. St.-Maurice, and P.-L. Blelly (2005), The effect of E-region wave heating on electrodynamical structures, Ann. Geophys., 23, 2081-2094

Sofko, G., R. Schwab, M. Watanabe, C. Huang, J. Foster, and K. McWilliams (2007), Auroral post-secondary ions from the nightside ionosphere in the inner magnetosphere, J. Atmos. Sol. Terr. Phys., 69, $1213-1232$

Xu, L. (2003), SuperDARN-derived plasma convection comparison with other data and application to field-aligned current measurements, Ph.D. thesis, Univ. of Saskatchewan, Saskatoon, Saskatchewan, Canada.

Xu, L., A. V. Koustov, J. Thayer, and M. A. McCready (2001), SuperDARN convection and Sondrestrom plasma drift, Ann. Geophys., 19, $749-759$.

Yau, A. W., H. G. James, and W. Lui (2006), The Canadian Enhanced Polar Outflow Probe (e-POP) mission in IWS, Adv. Space Res., 38(8), 18701877.

R. A. D. Fiori, R. G. Gillies, G. C. Hussey, K. A. McWilliams, G. J. Sofko, and J.-P. St.-Maurice, Institute of Space and Atmospheric Science, University of Saskatchewan, 116 Science Place, Saskatoon, SK S7N 5E2, Canada. (rob.gillies@usask.ca)

P. Ponomarenko, Space Physics Group, University of Newcastle, University Drive, Callaghan, NSW 2308, Australia. 